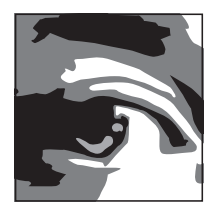

\title{
The UN High-Level Commission on Health Employment and Economic Growth: The Opportunity for Communities and their Primary Health Systems
}

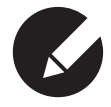

Judith Shamian, PhD

President Emeritus, International Council of Nurses

Professor and Co-investigator with the Nursing Health Services Research Unit, Lawrence S. Bloomberg Faculty of Nursing, University of Toronto

Toronto, ON

Kate Tulenko, PhD

Vice President for Health Systems Innovation

IntraHealth International

Washington, DC

Sandra MacDonald-Rencz

Healthcare Consultant

Former Nursing Executive and Senior Director, Health Care Policy and Programs

Directorate, Strategic Policy Branch, Health Canada

Ottawa, ON

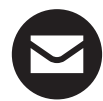

Correspondence may be directed to:

Judith Shamian

E-mail: judith.shamian@icloud.com 


\title{
(
}

\begin{abstract}
Focusing on the UN High-Level Commission on Health Employment and Economic Growth, this paper examines its potential impact on primary healthcare to communities. It contains a set of curated interviews with key decisionmakers who are determining how health workers are trained and employed all over the world. The commentaries come from individuals who have either been or have not been directly involved in the work of the Commission, exploring the necessary actions needed in support of implementing these recommendations, highlighting the ultimate potential impact at the local level - health systems and health workers working in communities and their primary health systems. Please note that the full submissions for these individuals are contained in Appendix 1 (available at: www.longwoods.com/content/25309).
\end{abstract}

\section{Introduction to Primary Healthcare to Communities ( $\mathrm{PHC}_{2} \mathrm{C}$ )}

This edition of World Health \& Population is focused on the theme of bringing primary healthcare to communities (PHC2C). As the countries of the world focus on achieving Universal Health Coverage (UHC) (WHO 2013) and Sustainable Development Goals (SDGs) (United Nations General Assembly 2015), it has become clear that primary healthcare plays an essential role in ensuring that all people have access to healthcare. By their non-acute nature, preventive and primary care can often be deferred and often is deferred by people with few resources. This leads to a demand bias for emergency and referral-level care, which is ultimately more expensive and leaves people with worse health.

We start with the UN High-Level (HL) Commission on Health Employment and Economic Growth, because it cuts across all aspects of health systems and their impact on the wider world, situating PHC2C within this greater context. This introductory paper is presented as a collection of curated interviews with key decision-makers who are determining how health workers are trained and employed all over the world.

\section{What is the UN HL Commission on Health Employment and Economic Growth?}

Attaining SDGs and UHC are among the leading challenges facing all countries. In support of the SDGs, the UN HL Commission on Health Employment and Economic Growth was established by UN SecretaryGeneral Ban Ki-moon in March 2016, with a final report of findings submitted on September 20, 2016. It was co-chaired by Presidents from France and South Africa with co-vice chairs from World Health Organization (WHO), Organisation for Economic Co-Operation and Development (OECD) and the International Labour Organization (ILO) and 19 Commissioners, each with collaborators to facilitate their work.

The establishment of the Commission is historical as the Commission was established by the UN, with a secretariat of three global organizations: WHO, ILO and OECD and co-chaired by heads of states. As such, it is essential to realize that the main impact of such a commission and its report is that it engages heads of states who put their power behind the key messages and recommendations. Far too often, these types of recommendations originated from the health and social sector, 
and were considered self-serving. Second, and equally essential, is the change of the traditional narrative. This report debunks the myth that healthcare is an expense and advances the evidence-based message that investing in healthcare workers is investing in the economic growth and prosperity of a country.

The task of the Commission was to make recommendations to stimulate and guide the creation of at least 40 million new jobs in the health and social sectors, and to reduce the projected shortfall of 18 million health workers, primarily in low- and lower-middle income countries, by 2030. However, the task is not to just call for more health workers. Rather, it was felt that targeted investment in health systems, including the health workforce, would promote economic growth along other pathways: economic output, social protection and cohesion, innovation and health security; recognizing that health workers are the cornerstone of a resilient health system. All are necessary to achieve both UHC and SDGs.

The Commission was supported in its work by an Expert Group whose main responsibility was to provide evidence-based information to the commissionaires that could inform the recommendations. The membership was drawn from the disciplines of economics, education, health, human rights and labour, and in developing its report (WHO 2016), the Commission received submissions, held consultations and commissioned policy briefs (All policy briefs are forthcoming in: Buchan et al. 2016). The Commission itself was composed of a diverse set of personalities from politicians, to Nobel prize winners and leaders from the global health community. The Commission report makes ten recommendations in support of SDGs. Six recommendations relate to what needs to be changed in health employment, health education and health service delivery to maximize future returns on investment. The remaining four recommendations focus on how to enable the necessary changes through financing, partnerships, migration and data.
Implementing the Commission's ten recommendations will require the support and collaborative efforts of political leaders and policy setters at the local, national, regional and international decision-making levels working with their respective stakeholders towards implementing the recommendations.

\section{Reflections on the Commission}

This paper reflects on whether the report will achieve the goal set out by the Commission, whether it will indeed lead to increased investment in the health workforce and whether this will lead to health system strengthening, especially at the community level. We felt that an important element of the article should be commentaries from individuals who have been directly involved in the work of the Commission and those who have not, exploring the necessary actions needed in support of actioning these recommendations, highlighting the ultimate potential impact at the local level - in health systems and health workers working in communities and their primary health systems.

There is work under way to continue to build commitment, draw up action plans and track systems to make every effort for this report to be enacted on so that economic development and health outcomes enhancing UHC and attaining SDGs can be reached by 2030 .

Please note: The following are excerpts taken from the commentaries. The complete questions and the respondents' full commentaries are found in Appendix 1 (available at: www.longwoods.com/content/25309). The invited experts as described below reflect three groups: (1) government; (2) global agencies; and (3) professionals.

\section{Perspectives from the Commission}

The first group of commentators were individuals directly involved in the Commission: one a Commissioner, the second a collaborator for one of the cochairs and finally a member of the expert group of the Commission. We asked 
this group to reflect upon actions occurring within their countries in support of the Commission work and what the impact might be at $\mathrm{PHC} 2 \mathrm{C}$.

Full biographies of each interviewee are available in Appendix 2 online at: www.longwoods.com/content/25309.

Bent Høie, Minister of Health and Care Services, Government of Norway, Oslo, Norway, and a Commissioner

"Different actions and policies will be needed for countries depending on their current health workforce needs and their role in the international health workforce market. Nevertheless, health ministers and their bureaucracies should work together with other ministries and develop a shared understanding of the Commission and what it means for them.

"Prevention, as we know, is more efficient than cure. Families having access to a health clinic with basic essential staffing and basic essential equipment and medicines gives a lot more back to the people and the economy than a fraction of the population having access to specialized care in the larger cities. Equitable access to prevention and basic care is essential. We have heard this before, but the major advantage this Commission presents is an economic growth context. I believe that this can be crucial for the primary healthcare agenda being picked up by heads of government."

\section{Dr. Benoit Vallet, Director General for}

Health, Ministry of Social Affairs and

Health, Government of France, Paris, France, and Collaborator for one of the Co-Chairs of the Commission "The HL Commission on Health

Employment and Economic Growth should pave the way for future collaborations between all relevant stakeholders, from all those different sectors. Indeed, the mission of the Commission is unprecedented and is at the heart of the SDGs. This new approach goes beyond the health sector and has helped develop a new interagency and intersectoral approach to health professionals.

"The global agenda should thus pave the way for a new reflection at national and local levels, to set up a global framework gathering not only governments but also all relevant stakeholders. This implies sharing information, developing a common language and improving capacity building at regional, national and local levels. Civil society and communities need to be involved to help transform healthcare systems and strengthen training models towards: redefining new models of health systems, with a stronger focus on prevention and an integrated approach on health systems strengthening and preparedness for health crises."

Dr. David Weakliam, Global Health Lead in the Irish Health Service Executive, Dublin, Ireland, and a member of the Expert Group "The power of the Commission lies in the way it brings an economic lens to the health workforce. What the report demonstrates is not just that the health workforce yields an economic benefit, but that the most efficient investment in the workforce is the one which will deliver UHC and improve health and well-being. It presents a clear message to all countries that the curative care model is unsustainable due to demographic changes and rising costs of healthcare, and that all countries will benefit from shifting to a community-based model.

"Primary healthcare is not a new approach but countries have not made the investments needed to make it work. By underpinning the approach with an economic argument, the Commission report can influence governments to reform health services away from hospital-based care towards a focus on prevention and community-based primary care with special attention to underserved areas. The Commission has described a range of pathways by which the health system and health workforce contribute to economic 
growth. These can persuade policy makers outside the health sector that investing particularly in a community-based primary care system will increase employment of women and youth, reduce social inequalities, enhance health security and drive inclusive economic growth."

\section{Perspectives from partner organizations}

The second group of commentaries are from individuals whose NGO CEO was co-vice chair of the Commission. These organizations have also committed to collaborative follow-up in support of the recommendations. They were also co-authors of several of the policy briefs referenced by the Expert Group report. We asked these individuals to reflect on the success of the Commission and their organization's commitment forward.

\section{Akiko Meada, PhD, Senior Health Economist, OECD, Paris, France}

"A major objective and achievement of the Commission Report was to broaden the policy dialogue beyond the health sector and to work across silos. Hence, health employment was not seen just as an instrument to ensure that health services are delivered, but also as an important part of the general labour market.

"The OECD will work with emerging economies and OECD member countries, in close cooperation with WHO and ILO, in ensuring a coherent approach and sharing knowledge and cross-fertilization of policies with all the countries across the globe, and in enabling low- and middle-income countries to skip a generation of health reforms as they work to achieve universal health coverage."

James Campbell, Director of the Health Workforce Department, WHO, Geneva, Switzerland

"The Commission underlined the unprecedented opportunity for tangible socioeconomic gains to be achieved by investing in the health and social workforce, recognizing the health and social sector as a major and growing employer and force multiplier for inclusive growth.

"The Commission was conceptualized and planned as an interagency collaboration. The partnership has evolved into the development of a joint action plan that specifies deliverables that will leverage the institutional strengths and mandates of each agency to the greatest effect to enable an enhanced platform of intersectoral cooperation to amplify national, regional and international health workforce action and investments.”

\section{Perspectives from research and policy}

The third and final group of commentaries are from researchers and NGO policy staff who were not directly involved in the work of the Commission. We asked these individuals to reflect upon whether the recommendations will make an impact within the workforce.

Dr. Jill White, Professor, Faculty of Nursing and Midwifery, Fellow of the University of Sydney Senate, Director of the USU Board, University of Sydney, Sydney, Australia "As a nurse, academic, mother, community member and global citizen I welcome the recommendations of the report. When I look at each one I am a mixture of grateful and depressed. Grateful that, although we are by no means perfect, gender equity and women's rights are further ahead than many countries; we have an excellent and accessible education system; we have a high-quality healthcare system with excellent hospitals and health professionals educated at well regarded universities; we have cutting edge technologies; and blessedly we are largely conflict free. Less joyful are the current political realities in relation to healthcare and the ramifications for the recommendations of the Report. Whilst there is some political appetite for moving to an integrated health and social care system, the system complexity and short electoral cycles make this profoundly difficult." 


\begin{abstract}
Howard Catton, Director, Nursing and Health Policy, International Council of Nurses, Geneva, Switzerland

"The UN Commission has made a bold, compelling and evidence-based case for investment in the health workforce. However, the change in political mind-set required to deliver this should not be underestimated. Many countries are still recovering from the global economic downturn and have implemented austerity programs to cut public spending. The environment could probably not be tougher in which to ask political leaders to invest in the health workforce. A significant risk is that investment in the health workforce could be focused on quickly increasing the supply line through producing new cadres of substitute workers. All of which means that the action plan must be about developing strategies to actively engage all stakeholders and developing a shared ownership for action."
\end{abstract}

\section{Reflections of the Authors}

It is essential to understand that dealing with global health issues, whether hunger, poverty, health or others, requires a multisectorial, multiagency approach including the professionals who are knowledgeable and familiar with the situations on the ground. The work of this Commission should serve as an exemplar on how the many stakeholders can be brought together to serve both evidence-based and political recommendations.

The Commission in its final report and set of recommendations worked to foster health workforce-related commitments across five SDGs, specifically SDG 1 (poverty elimination), SDG 3 (good health and well-being), SDG 4 (quality education), SDG 5 (gender equality) and SDG 8 (decent work and economic growth). In doing this, it has charted an ambitious path, making the link of health employment as an economic driver for a country. Drawing upon the Expert Group's work and supported through a series of policy briefs, the report has called for a fundamental transformation in the development and support of the global health workforce, all necessary for achievement of the SDGs. It recognizes the need for labour market policies that ensure investments in building skills and creating jobs that are linked to maximise inclusive economic growth, and a robust health system, one based upon a strong community-based primary healthcare.

As noted by each of the respondents, we need to transform and expand the education and training of health workers throughout their careers to equip them with the skills required to meet needs, particularly in geographic areas where there are few health workers. We will also need to reform the way health services are provided, shifting from hospital-based curative care to communitybased services that focus on preventing disease, and that are built around the needs of people, not diseases.

Also, as noted in the commentaries, stronger international cooperation will be needed to address workforce issues and boost global security. Also, as noted in the Commission's report, countries must work together to build a sustainable global health workforce. Demand in high- and middleincome countries will continue to drive health worker migration. Countries will need to cooperate to ensure that the international migration of health workers benefits both the countries of origin and destination, and that their rights are protected.

Several of the commentators flagged the need for focus on the creation of decent jobs that could potentially transform currently informal caring jobs without salary, benefits or protections into formal jobs with regular pay, benefits such as health insurance and retirement savings and labour protections such as safe working environments and freedom from sexual harassment, often seen as important issues in primary and continuing care systems. In addition, the decent jobs focus would help create career ladders that enable top performers to advance in education, responsibility and compensation. 
Also, there needs to be a strong commitment from many levels of government working in partnership with stakeholders to facilitate the uptake of this report. All stakeholders will have a critical role to play and need to work together across sectors of education, health, labour, finance and foreign affairs to invest in and transform current health workforce models to be sustainable and fit-for-purpose for health systems at the community and local levels, now and into the future.

Finally, it will be critical to engage the private sector in the implementation of the Commission's recommendations. The vast majority of the countries that have achieved UHC have done so through blended publicprivate systems. There are opportunities to engage the private sector throughout the lifespan of the health worker, including policy, financing, education and service delivery.

To attain UHC and SDGs and have the right healthcare workforce, everyone relevant to the topic has to have a seat at the table and come to shared agreement which will strengthen the economic, health and social well-being of all nations.

\section{Conclusion and Key Messages}

While the Commission report focuses on the whole health system, there are key messages for PHC2C:

- The report advocates for a paradigm shift in viewing investments in healthcare and health workers as an economic driver not a cost factor.
- Based upon that, it builds the case for investments in health employment throughout the health system, highlighting the importance of decent jobs with decent pay and the need for investment in primary healthcare knowledge and skills development.

- Partnerships across the health system will be important to create sustainable community health systems.

- This will require collaboration between all stakeholders: governments, health system managers, researchers, health professionals, NGOs, trade unions and consumer groups.

\section{References}

Buchan, J., I. Dhillon and J. Campbell, eds. 2016. Health Employment and Economic Growth: An Evidence Base. Geneva, CH: World Health Organization. Retrieved October 2, 2017. <http:// www.who.int/hrh/com-heeg/com-heeg-policy_ briefs/en/>.

United Nations General Assembly. 2015. "Transforming our World: The 2030 Agenda for Sustainable Development." A/70/L.1, 18 September.

World Health Organization (WHO). 2013. World Health Report 2013: Research for Universal Health Coverage. Retrieved October 2, 2017. <http://apps.who.int/iris/bitst ream/10665/85761/2/9789240690837_eng.pdf>.

World Health Organization (WHO). 2016. "Final Report of the Expert Group to the High-Level Commission on Health Employment and Economic Growth.” Retrieved October 2, 2017 <http://www.who.int/hrh/com-heeg/reports/ report-expert-group/en/>.

\section{Longwoods.com}

